\title{
Suicide prevention and suicidal behavior
}

\author{
Carlos Campillo Serrano* and Germán Fajardo Dolci
}

Faculty of Medicine, Universidad Nacional de México, Mexico City, Mexico

\begin{abstract}
In Mexico, suicidal behavior is a matter of concern because, although the rates of death by suicide are below global mean (11.4 vs. $4.1 \times$ 100,000 population), between 1970 and 2007 they increased by $175 \%$, especially among young people, in whom it is the third leading cause of death. For this reason, several preventive actions have been developed but have not had the expected success, because they are poorly designed. They lack a uniform and clear case definition. Their approach is reductionist, it focuses only on the public health aspect and does not go beyond traditional plans of primary, secondary and tertiary prevention. This review aims to offer different options, such as adopting the case definition provided by Atlanta's Centers for Disease Control and Prevention (CDC). It aims to broaden the vision in order to include philosophical, psychosocial and psychiatric aspects, as well as to include, as a theoretical framework, the "diathesis-stress" psychological model and propose a population-based intervention preventive strategy.
\end{abstract}

KEY WORDS: Suicide. Suicidal behavior. Prevention.

\section{Prevención del suicidio y la conducta suicida}

\section{Resumen}

En México la conducta suicida es una preocupación porque, aunque las tasas de suicidio consumado están por debajo de la media mundial (11.4 vs. 4.1 x 100,000 habitantes), entre 1970 y 2007 aumentaron un 175\%, sobre todo a expensas de los jóvenes, en los cuales es la tercera causa de muerte. Por tal motivo, se han elaborado varias acciones preventivas que no han tenido el éxito esperado, porque están mal planteadas. Carecen de una definiciones de caso uniforme y clara. Su enfoque es reduccionista, se apega solo al de la salud pública y no salen del esquema tradicional de prevención primaria, secundaria y terciaria. La presente revisión pretende ofrecer una opciones diferentes. Adoptar como definición de caso la de los Centros para el Control y la Prevención de la Enfermedades (CCD) de Atlanta. Ampliar la visión incluyendo aspectos filosóficos, psicosociales y psiquiátricos. Incluir como marco teórico el modelo psicológico «diátesis-estrés" y proponer como estrategia preventiva "las intervenciones por poblaciones".

PALABRAS CLAVE: Suicidio. Conducta suicida. Prevención.

\section{Introduction}

Suicide and suicidal behavior are universal phenomena. It is observed in all regions and cultures. The World Health Organization estimated that 804,000 people in the world committed suicide in 2012. Every
40 seconds, one person in the world dies by suicide. ${ }^{1}$ In Mexico, the rates of deaths by suicide are below the world average (11.4 vs. 4.1 per 100,000 population). ${ }^{2}$ Nevertheless, it has become a major public health problem, given that, between 1970 and 2007, the rates showed an increase of $175 \%$, at the expense
Correspondence:

${ }^{*}$ Carlos Campillo-Serrano

E-mail: ccs1944@gmail.com
Gac Med Mex. 2021;157:547-552

Contents available at PubMed

www.gacetamedicademexico.com

0016-3813/@ 2021 Academia Nacional de Medicina de México, A.C.. Published by Permanyer. This is an open access article under the CC BY-NC-ND license (http://creativecommons.org/licenses/by-nc-nd/4.0/). 
of young people, among whom it is already the third leading cause of death. ${ }^{3,4}$ Although different preventive programs have been proposed, unfortunately these have not been successful, despite the fact that suicide is one of the few mental health issues where effective and successful interventions can be implemented.

The proposed programs have not been successful because they are poorly planned: there is a lack of a uniform and clear case definition, the prevailing approach is reductionist, since it focuses only on public health and does not go beyond the traditional strategies of primary, secondary and tertiary prevention. ${ }^{5}$

This review aims to offer different alternatives. First, to adopt the case definition provided by Atlanta's Centers for Disease Control and Prevention (CDC); ${ }^{6}$ second, to broaden the approach to the issue by including philosophical, psychosocial and psychiatric aspects and, finally, to include, as a theoretical framework, the "diathesis-stress" psychological model 7 by proposing "population-based interventions" as a preventive strategy.

\section{CDCs case definition}

This conception is the most accepted and eclectic. It accurately describes the three degrees of suicidal behavior:

- Suicide: death caused by self-directed injurious behavior with any intent to die as a result of the behavior

- Suicide attempt: non-fatal self-directed potentially injurious behavior with any intent to die as a result of the behavior. It may not result in injury.

- Suicidal ideation: thinking, considering or planning to commit suicide.

\section{Sociocultural, philosophical and scientific vision}

The vision of suicide and suicidal behavior change according to different cultures and times. An example of this would be Japan in contrast to the countries of Judeo-Christian tradition. For the former, suicide is an act of personal dignity and national pride, as shown by samurais' hara-kiri, which prevails to this day. Let us remember that the great writer Yukio Mishima ${ }^{8}$ carried it out, in protest for the subjugation of his nation to the US. Conversely, for the Judeo-Christian culture, it is a reprehensible and condemnable act.
The perception of suicide changes with the times. During romanticism, it was considered acceptable when it was brought about by love. Johann Wolfgang von Goethe, leader of the romantic current, published The Sorrows of Young Werther, ${ }^{9}$ whose main character takes his life because his beloved does not love him back. The novel was a worldwide success, and had such an impact, that it generated a wave of suicides among men and women that came to alarm society. ${ }^{10}$ Something similar happened in our midst with the case of Manuel Acuña, a romantic poet and medical student who, by taking his life for the love of Rosario, ${ }^{11}$ unleashed a sort of self-inflicted death fashion. And it is just that one of the consequences of suicidal behavior is imitation; in 1974, American sociologist David Phillips called it "the Werther effect", alluding to the famous novel.

A suicide is a blow for those around the person and for society as a whole, which sometimes is also shaken. Hence, it is also a powerful political tool, as illustrated by the iconic self-immolation of Buddhist monk Thich Quang Duc, ${ }^{12}$ who soaked himself with gasoline and set himself on fire in public to protest for the treatment received by Buddhists from South Vietnamese government. The picture of his suicide appeared all around the world and somehow contributed to the turnaround the Vietnam war would take.

The philosophical perspective of suicidal behavior shows the different contrasts in the face of existence. Christians condemn it, because for them God is the owner of our life and only he can dispose of it. On the other hand, there are those who consider it the highest act of freedom of man. Romanian philosopher Emil Cioran used to say that "the beauty of suicide is that it is a decision. Deep down it is highly ingratiating being able to suppress oneself". ${ }^{13}$

The scientific perspective on this issue initiates in the $19^{\text {th }}$ century, with Émile Durkheim, a positivist sociologist and author of Suicide, ${ }^{14}$ a book in which he maintains that the suicidal act is a social phenomenon that goes beyond the individual. He was the first to use statistics to study the issue (let's not forget that current epidemiology is Durkheim's direct heir).

\section{Psychological and psychiatric perspectives}

Addressing the multiple angles offered by the psychological and psychiatric perspectives helps to understand the self-destructive behavior of people as individuals. 
From the psychological point of view, the act of taking one's own life can be read in different ways: a desperate action of someone who finds no other way out, an attempt to communicate or attract attention, an aggression with a message addressed specifically to someone, a way to unload resentments and hostile wishes. For Freud, the father of psychoanalysis, every suicide is a frustrated homicide, ${ }^{15}$ i.e., it is carried out by someone who unconsciously chooses to take his own life, rather than taking it from another.

Suicidal unconscious also manifests itself in highrisk behaviors, especially among adolescents, in whom there is perhaps no self-destructive intention, but there is a defiance or a challenge to life consisting of driving cars at high speed, practicing sports that involve high dangers, etc. The pursuit of strong emotions brings them closer to death, and the closer they get, the more exciting life is. Therefore, it is not surprising that the mortality rate in this age range is higher than in the general population, as it is also shown by health and life insurance premiums. ${ }^{16}$

One question that is often asked when a person has attempted suicide is how serious the act was: did the person actually try to kill himself or did he simply try to attract attention? Despite the complexity of the answer, the question appears to be necessary in order to better know the motivations of suicidal behavior and to understand those who manifest it. To begin with, every suicidal act is ambivalent, ${ }^{17}$ since, in human beings, forces in favor of life and others in favor of death coexist. Far from a black/white contrast, there are gradients. Some people are more determined than others to kill themselves. The Russian roulette game is a good example. In a six-round revolver, the most determined leave only one empty chamber; the least determined, leave five or none. Therefore, one should not lose sight of the fact that that people who decide to kill themselves, no matter how determined they are, always leave a loophole open that can save them.

That is why the question about the seriousness of the intention of somebody to take his own life must be carefully answered. Rating the degree of "seriousness" is a complex matter and often involves value judgments. Typically, the seriousness of the act is established by the lethality of the chosen method. Therefore, with this logic, the most serious are by those who use firearms, throw themselves from the top of a building or hang themselves. Nevertheless, most resort to methods in which rating the degree of lethality is not easy, such as carbon monoxide from the oven in the house or car, cutting their veins, ingesting medication overdoses, etc. For a correct evaluation of a suicide attempt it is necessary to know down to the last detail of the act and not simply restricting to the lethality of the method. The value judgment implied by the question we have been referring to, unfortunately, divides people in two extremes: successful attempts are even viewed with respect and those that only attract attention tend to be severely condemned. In fact, all suicides, successful or not, are like a cry of despair, a wake-up call to those around those who reach that extreme. Therefore, it is advisable not to ask that kind of question in the first place and not lose sight of the anguish that is behind these behaviors.

A psychological aspect that is also relevant for people who tried in vain to kill themselves is the concept of crisis. ${ }^{18}$ This is defined as a mental disorganization due to a problem that the individual is not able to solve through usual methods. It is generally a situation that surprises or deeply confuses the subject and that can turn into a vital two-way crossroads, going down or getting ahead. In other words, a suicide attempt well managed by professionals and close family and friends of the suicidal individual can become an opportunity to face and resolve pending issues and lead to further emotional growth. Conversely, if the attempt is minimized or not properly treated, the outcome can be fatal.

It should be borne in mind that the majority of people who manifest suicidal behaviors suffer or have previously suffered from some mental disorder such as depression, bipolarity, schizophrenia, alcoholism, drug abuse, etc. ${ }^{19}$ Thus, the suicidal act is an exacerbation of a pathology that comes from long ago. Often there are previous attempts, and, in certain cases, a history of relatives who took their own lives.

An approach that has helped to understand people who have taken their own lives is psychological autopsies, which consist of reconstructing the behavior of these people on the days prior to their death. Psychological autopsies have shown that, before the event, there were warning messages or signs, which were not properly perceived by people around, including doctors themselves and health personnel. Different studies show that between 30 and $50 \%$ of suicidal individuals had been in contact with a doctor or psychiatrist. ${ }^{20}$ This finding has stimulated the creation of instruments intended to identify the risk and prevent suicidal behaviors. However, neither of them has always turned out to be entirely efficacious. Despite preventive intervention, there are people who end up 
taking their own life. Thus, experience shows that it is more effective to detect the psychopathology underlying the intention and proceed to treat it, always warning the person concerned and those closest to him on the importance of maintaining a vigilant attitude.

\section{An emblematic case: Sylvia Plath}

One of the most widely studied suicide cases is that of American poet Sylvia Plath (1932-1963). ${ }^{21}$ Her case clearly illustrates the issues herein described. Her father, with whom she had a close relationship, died when she was five. At age 21 (1953), she had her first suicide attempt and was admitted to a psychiatric hospital, where she received electroshocks and insulin shocks, as well as psychoanaIytic therapy. In 1962, she had a serious car accident she got out alive from, but that can already be classified, given that she was behind the wheel, as risky behavior. That same year she separated from her husband, also poet Ted Hughes (1930-1998). Paradoxically, the separation coincides with a period of great literary productivity for her, which, according to her medical history, suggests a hypomanic episode, since she subsequently suffers the depressive condition that ends up in her suicide on February 11, 1963. There is no doubt that Sylvia Plath suffered from bipolar disorder, which is known to have a strong genetic makeup; it is hardly surprising that her youngest son, born in 1962, took his own life at age 47.

Sylvia Plath's suicide appears to leave no doubt that she was determined to die. She stuck the head in the stove's oven and turned it on to inhale the gas, a fairly common method among females who attempt suicide in the UK. However, analyzing the situation more closely, her determination is not that strong. She knew that in a few minutes, as every day, the always punctual nanny of her children would arrive, but that day she failed: a public transport congestion delayed her arrival. When she entered the house, she was the one who discovered the body.

Sylvia's suicide had a huge repercussion. Her status as a woman, her eventful life and her poetic talent turned her into an emblem for the feminist movement, which blamed Ted Hughes for her death, for having abandoned her for her best friend. Condemned to social ostracism, Hughes was rehabilitated by the quality of his own poetic work.

\section{A different preventive strategy}

The most appropriate theoretical reference to guide preventive interventions is the "stress-diathesis" psychological model that is used both in mental disorders and in some social phenomena. ${ }^{22}$ The word diathesis is derived from Greek ( $\left.\delta t_{\alpha}^{\prime} \theta \varepsilon \sigma l \varsigma\right)$, and it means predisposition, sensitivity or weakness. This model is useful to explain how biological or genetic attributes (diathesis) interact with environmental influences (stressors) to generate a disorder such as suicidal behavior. ${ }^{22}$

The preventive strategy of this approach, instead of traditional primary, secondary and tertiary strategies, consists of the so-called population-based interventions, which allow the design of more precise and effective actions. Said interventions are aimed at three types of populations: a) universal intervention, which encompasses the general population; b) selective interventions, which focus on high-risk groups, and c) recommended interventions, which are not aimed at groups, but at very high-risk individuals.

\section{Universal interventions}

This type of interventions are aimed at the general population at different levels (national, state or regional) and at specific groups (students, older people, sick people, etc.). The national interventions that have shown effectiveness, although, curiously, they were not expressly designed with the purpose to prevent suicide, are: restriction of the purchase and sale of firearms, use of automotive catalysts to reduce the production of carbon monoxide, change from conventional domestic gas to natural gas. Other measures at this level and expressly aimed at the business at hand are: restricted access to the roofs of tall buildings and construction of protective fences on road bridges to prevent people from jumping from there. With the same purpose, the number of pills in controlled drug packages has been reduced and their presentation has changed to plastic blister packs. While these are smart measures, no scientific evidence on their efficacy has yet been established.

Other national preventive strategies consist of offering access to medical care, through public health services, to high-risk people, such as those who suffer from mental disorders and/or consume alcohol and drugs.

The measures focused on specific sectors of the population include school-based educational campaigns for students, and for teachers to be able to identify and help those who are in crisis, as well as crusades to combat bullying that, although originally were not conceived against suicide, have helped to 
reduce the rates of this type of behavior among students. ${ }^{23}$

\section{Selective strategies}

This type of strategies are aimed at the most vulnerable populations, which include, in addition to addicts, people newly diagnosed with a serious illness, especially at old age, convicts and many individuals who live on the streets.

Suicidal risk in mentally ill individuals is ten times higher than in the rest of the population, whatever the type of ailment. Since many of these disorders are rarely identified and, therefore, not treated at primary care services, training programs have been developed in order for general practitioners to recognize and treat people with depression. These programs have been shown to increase the prescription of antidepressants and to decrease the rates of suicidal behavior.

Suicidal risk increases among those who have just been diagnosed with a serious disease, especially neurological or neoplastic. For this reason, evaluating them with special care is advised. Other high-risk populations are those of people who live on the streets, particularly when they are young, as well as former convicts who have just been released. Unfortunately, these risk groups have not received the necessary attention.

Other selective interventions are especially recommended in the case of people who have attempted suicide or have attended some medical service for suicidal ideation. A statistical review found that $16 \%$ of people who tried to take their own life tried it again within one year without fatal consequences, but $2 \%$ were successful. However, nine years later, $7 \%$ succeeded. ${ }^{24}$ Thus, previous suicide attempts, especially when repetitive, are the main risk factor and, therefore, a signal one should be alert of.

In general, most people who attempt suicide are usually taken for care to the emergency departments of general hospitals, where the ideal scenario would be having a system trained in handling critical situations. Rarely does the intervention of medical personnel in these situations have a satisfactory result, and it is therefore common for the person to be discharged without the core of his problem having been identified.

Unfortunately, so far there is no clear evidence on which of these interventions are useful for prevention. The one that seems to offer better results is cognitive behavioral therapy. Other strategies that have yielded some results are patient follow-up through periodical letters or phone calls.

\section{Conclusions}

Suicidal behavior prevention can be effective if a uniform and eclectic case definition is adopted, if it is approached from a broad perspective that is not limited to the public health vision and if a more operative interventional model is used and adapted to such a complex behavioral phenomenon.

\section{Funding}

This article did not receive any funding.

\section{Conflict of interests}

The authors declare that they have no conflicts of interest.

\section{Ethical disclosures}

Protection of human and animal subjects. The authors declare that no experiments were performed on humans or animals for this research.

Confidentiality of data. The authors declare that they have followed the protocols of their work center on the publication of patient data.

Right to privacy and informed consent. The authors declare that no patient data appear in this article.

\section{References}

1. Organización Panamericana de la Salud, Organización Mundial de la Salud. Prevención del suicidio: un imperativo global [Internet]. Organización Panamericana de la Salud, Organización Mundial de la Salud; 2014 [cited: Sep 24, 2019]. Available at: https://www.paho.org/es/documentos/ prevencion-suicidio-imperativo-global

2. Borges G, Nock MK, Medina-Mora ME, Benjet C, Lara C, Chiu WT, et al. The epidemiology of suicide-related outcomes in Mexico. Suicide Life Threat Behav. 2007;37(6):627-40.

3. Borges G, Orozco R, Villatoro J, Medina-Mora ME, Fleiz C, Díaz-Salazar J. Suicide ideation and behavior in Mexico: Encodat 2016. Salud Publica Mex. 2019;61(1):6-15.

4. Borges G, Benjet C, Orozco R, Medina-Mora ME. The growth of suicide ideation, plan and attempt among young adults in the Mexico City metropolitan area. Epidemiol Psychiatr Sci. 2017;26(6):635-43.

5. Wilcox HC, Wyman PA. Suicide prevention strategies for improving population health. Child Adolesc Psychiatr Clin N Am. 2016;25(2):219-33.

6. Crosby $A E$, Ortega L, Melanson C. Self-directed violence surveillance. Uniform definitions and recommended data elements, Version 1.0 [Internet]. Atlanta, GA: National Center for Injury Prevention and Control, Division of Violence Prevention; 2011. Available at: http://www.cdc.gov/ violenceprevention/pdf/self-directed-violence-a.pdf

7. Hankin BL, Abela JRZ. Development of psychopathology: A vulnerability-stress perspective. Sage; 2005.

8. Mishima Yukio [Internet]. Encylopaedia Britannica; 2020. Available at: https://www.britannica.com/biography/Yukio-Mishima

9. Goethe J. Penas del joven Werther. Alianza Editorial; 2012. 
10. Phillips D. Efecto Werther [Internet]. Wikipedia. Available at: https:// es.wikipedia.org/wiki/Efecto_Werther

11. Manuel Acuña, el último gran poeta del romanticismo en México: Marco Antonio Campos [Internet]. Gobierno de México, Secretaría de Cultura; August 27, 2013. Available at: https://www.gob.mx/cultura/prensa/manuel-acuna-el-ultimo-gran-poeta-del-romanticismo-en-mexico-marco-antonio-campos

12. Thich Quang Duc [Internet]. Wikipedia; 2020. Available at: https://es.wikipedia.org/wiki/Thích_Qu[ng_Đロc

13. Emil Cioran [Internet]. Wikiquote; 2020. Available at: https://es.wikiquote. org/wiki/Emil_Cioran

14. Durkheim E. El Suicidio (Spanish Edition). CreateSpace Independent Publishing Platform; 2017.

15. Ferreyra L. Suicidios y Freud: Conceptualizaciones sobre el suicidio en ensayos freudianos. Anu Investig. 2017:3(2):488-506.

16. Klonsky ED, Saffer BY, Bryan CJ. Ideation-to-action theories of suicide: a conceptual and empirical update. Curr Opin Psychol. 2018;22:38-43.

17. Kleiman EM, Nock MK. Real-time assessment of suicidal thoughts and behaviors. Curr Opin Psychol. 2018;22:33-7.
18. González de Rivera Revuelta JL. Psicoterapia de las crisis. Rev Asoc Española Neuropsiquiatría. 2001;79:37-51.

19. Robins E, Murphy GE, Wilkinson RH, Gassner S, Kayes J. Some clinical considerations in the prevention of suicide based on a study of 134 successful suicides. Am J Public Health Nations Health. 1959;49(7):888-99.

20. Turecki G, Brent DA. Suicide and suicidal behaviour. Lancet. 2016;387(10024):1227-39.

21. Alvarez A. The Savage God: A study of suicide. London: Penguin; 1971.

22. Lazarus RS. From psychological stress to the emotions: A history of changing outlooks. Annu Rev Psychol. 1993;44:1-21.

23. Niederkrotenthaler T, Stack S, Till B, Sinyor M, Pirkis J, García D, et al. Association of increased youth suicides in the United States with the release of 13 Reasons Why. JAMA Psychiatry. 2019;76(9):933-40

24. Owens D, Horrocks J, House A. Fatal and non-fatal repetition of selfharm. Br J Psychiatry. 2002;181(3):193-9. 